\title{
MENINAS NAS CIÊNCIAS: DESENVOLVENDO HABILIDADES PARA \\ A INSERÇÃO NAS ENGENHARIAS DESDE A ESCOLA
}

Alineda RosaOrtiz-aline-r-ortiz@outlook.com

Universidade de Santa Cruz do Sul - UNISC

Av. Independência, 2293 - Universitário

99360-000 - Barros Cassal - RS

Fernanda Theisen -fernandatheisen98@hotmail.com

Universidade de Santa Cruz do Sul - UNISC

Av. Independência, 2293 - Universitário

96835-070 - Santa Cruz do Sul - RS

Leticia Diesel -Idiesel@unisc.br

Universidade de Santa Cruz do Sul - UNISC

Av. Independência, 2293 - Universitário

96815-900 - Santa Cruz do Sul - RS

Pâmela Rodrigues de Oliveira - pamelarodrigues2@unisc.br

Universidade de Santa Cruz do Sul - UNISC

Av. Independência, 2293 - Universitário

96820-990 - Santa Cruz do Sul - RS

Pâmela Cristina Tatsch-pamela.cristina.tatsch@hotmail.com

Universidade de Santa Cruz do Sul - UNISC

Av. Independência, 2293 - Universitário

96845-134 - Santa Cruz do Sul - RS

Resumo: A engenharia é impulsionadora do desenvolvimento e tem como finalidade proporcionar a sociedade soluções para significativos problemas. Entretanto, verifica-se que nesta área, tida como essencialmente masculina, o perfil de distribuição é muito desigual. Assim, ampliar a participação feminina em atividades científicas na área tecnológica, principalmente na engenharia, é uma necessidade que demanda ações específicas. Desta forma, o projeto Meninas nas Ciências: Desenvolvendo Habilidades nas Engenharias da Universidade de Santa Cruz do Sul e financiada pelo CNPq, visa desenvolver habilidades $e$ conhecimentos de engenharia, estimulando e promovendo o incentivo da atuação feminina na área. Foram selecionadas professoras e alunas de cinco escolas públicas do município de Santa Cruz do Sul, e que desenvolvem projetos específicos que ocorrem em oficinas realizadas dentro dos laboratórios de engenharia da universidade e nas escolas. Buscando o conhecimento e a descoberta dos princípios básicos das engenharias, através da utilização de kits de montagens, que permitem a simulação de objetos e construção de experimentos, ocorre uma interação com os conteúdos que são abordados em disciplinas do ensino médio e do ensino superior. Assim, o projeto proporciona um ambiente de conhecimento técnico-científico, desenvolvimento do senso crítico e a experimentação dos conceitos estudados, com foco na área tecnológica e incentivo ao ingresso das alunas no campo das ciências e engenharias. Servindo como impulsionador à inclusão das mulheres no mundo da ciência e do trabalho.

Palavras-chave: Engenharia, meninas, educação, empreender, inclusão social. 


\section{INTRODUÇÃO}

Há muitos anos as mulheres buscam estudar, serem independentes, construir carreira e obter maior inserção na sociedade e no mercado de trabalho, pois não querem ter suas vidas resumidas em serviços do lar. Moraes e Cruz (2018) ressaltam que as mulheres são maioria no ensino superior, porém a participação das mulheres na área das engenharias ainda se resulta a um menor percentual comparado aos homens. Sendo necessário identificar o motivo em questão para que possa surgir soluções e automaticamente novos índices dessa realidade. Retornando um pouco sobre a história, segundo Bruschini e Lombardi (2000), com o início das escolas militares se deu o início das engenharias no Brasil (na Bahia em 1696 e no Rio de Janeiro em 1811). Os civis tiveram acesso no século XIX, ressaltando que apenas os homens poderiam frequentar escolas militares, e como decorrência, a atuação nas engenharias. Apesar de se passarem muitos anos, ainda é possível observar alguns resquícios dessa época, uma certa barreira referente as mulheres nas áreas das engenharias. No século XX houve uma participação mais ativa da mulher no mercado de trabalho, e a partir de 1960 o Estado proporcionou uma qualificação das mulheres com bolsas, ensino superior e viagens. (Lousada e Cantarin, 2020) A cultura patriarcal inferioriza a mulher e empodera o homem. Em algumas empresas, homens e mulheres podem possuir o mesmo cargo, porém as mulheres devem se sobressair para ganhar destaque e serem promovidas, e alguns casos o salário é desigual mesmo obtendo as mesmas atribuições. Esta é uma realidade mundial e, enquanto alguns países buscam mudar esse índice, outros ainda estão evoluindo em passos lentos. Deve-se levar em consideração a cultura de cada lugar para avaliar os reais avanços. Schwantes e Andrade (2017) observam que a mulher não se vê pertencente ao mundo das Ciências Exatas, em toda sua formação, se sentindo excluída desse meio. Um fato relevante é sobre as brincadeiras na infância, que influenciam futuramente nas áreas de estudos e profissões escolhidas. Por exemplo, as meninas são estimuladas a brincar de boneca e casinha, enquanto os meninos brincam de carrinhos e jogos eletrônicos, que estimulam as descobertas tecnológicas. Lousada e Cantarin (2020) também falam sobre "vocação", a qual é bastante utilizada na escolha das profissões. Enquanto os homens escolhem áreas como por exemplo as Engenharias, as mulheres que tem na sua formação os ensinamentos de cuidar da casa e da família, portanto vão para as áreas da saúde e da educação. Com base nisso, surge o questionamento sobre como pode ser modificada essa realidade. Que tipo de ações pode ser desenvolvida para vencer essa resistência? E como trazer mais a presença feminina para a área das engenharias? Sempre existiram mulheres fortes, que queriam mudança, que lutavam por igualdade, que mesmo com críticas e julgamentos fizeram o que gostavam e acreditavam. Sejam elas cientistas, físicas, engenheiras, entre outras, que ousaram e persistiram fazer parte de um ambiente que predominava a presença masculina. Não se pode mudar tudo, mas se cada um fizer sua parte em busca de melhorias já é um grande avanço. Por citar a palavra avanço, é possível observá-lo na tabela 1 que mostra dados sobre os pesquisadores do CNPq ao longo dos anos. As mulheres se igualaram aos homens, porém essa pesquisa é de uma forma geral, é preciso aumentar os números especificamente na área das exatas, e com persistência é possível. 
Tabela 1 - Dados sobre os pesquisadores do CNPq de 1993 a 2016.

Pesquisadores por sexo (\%)
Distribuição percentual dos pesquisadores segundo o sexo
\begin{tabular}{|l|r|r|r|r|r|r|r|r|r|r|r|r|r|r|}
\hline Sexo & 1993 & 1995 & 1997 & $\mathbf{2 0 0 0}$ & $\mathbf{2 0 0 2}$ & $\mathbf{2 0 0 4}$ & $\mathbf{2 0 0 6}$ & $\mathbf{2 0 0 8}$ & $\mathbf{2 0 1 0}$ & $\mathbf{2 0 1 4}$ & $\mathbf{2 0 1 6}$ \\
\hline Masculino & ND & 61 & 58 & 56 & 54 & 53 & 52 & 51 & 50 & 50 & 50 \\
\hline Feminino & ND & 39 & 42 & 44 & 46 & 47 & 48 & 49 & 50 & 50 & 50 \\
\hline
\end{tabular}

Fonte: $\mathrm{CNPq}$

A palavra empreender remete a um negócio próprio ou empreendimento/empresa, mas analisando com uma visão mais ampla pode ser definido como uma sequência de verbos como sonhar, tentar, persistir e realizar. O projeto é um empreendedorismo, precisou de atitude para realizar uma ação e desenvolver métodos para realizar as atividades. Paulo Freire (1987) já dizia que: "Educação não transforma o mundo. Educação muda as pessoas. Pessoas transformam o mundo." Sendo assim, trilhando o caminho da Educação, o Projeto Meninas nas Ciências: Desenvolvendo Habilidades nas Engenharias busca despertar o interesse e desenvolver habilidades de meninas nas áreas de engenharias, desde a escola, para que almejam um futuro de forma consciente de suas escolhas e empreender. O projeto acredita assim como Lousada e Cantarin (2020), que a inserção das mulheres na ciência traz uma nova percepção que pode "abrir novos horizontes".

\section{METODOLOGIA E DESENVOLVIMENTO}

O projeto utilizou a metodologia de Aprendizagem Baseada em Problemas (ABP), amplamente utilizada nas instituições educacionais de ensino superior e básico nos últimos anos. Segundo Barrows (1986), o método ABP tem por base a utilização de problemas como ponto de partida para adquirir novos conhecimentos, na qual irá promover uma aprendizagem centrada no aluno, tendo os professores como facilitadores deste processo de produção do conhecimento. Também há oficinas, tanto na universidade como nas escolas, o desenvolvendo maquetes funcionais, através dos Kits Fischertecknics (fig. 1), com o acompanhamento de bolsistas e integrantes do projeto mais familiarizados com conceitos de engenharias. Nesse processo, os problemas são um estímulo para a aprendizagem e para o desenvolvimento das habilidades de resolução. Seguindo esta metodologia serão definidos momentos de apresentação dos problemas. Assim consegue-se simular situações que ocorrem na vida real.

Figura 1: Modelo dos Kits da Fischertecknics.

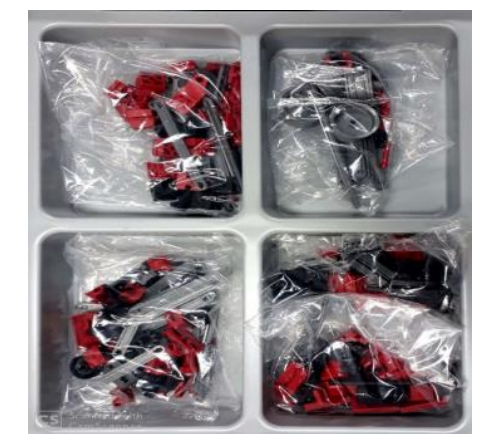

Fonte: projeto meninas nas ciências

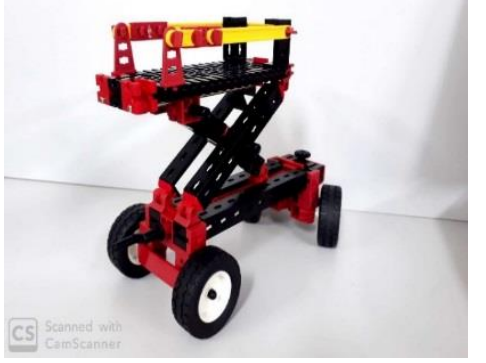

Fonte: projeto meninas nas ciências 


\section{OFICINAS NA PRÁTICA}

Após realizado a seleção das bolsistas, tiveram alguns encontros para ter o primeiro contato com as peças do laboratório da Engenharia de Produção, foram montados alguns kits para desenvolver a habilidade em manusear as peças e organizar as primeiras aulas propostas. As aulas são definidas a partir da montagem de um kit, no qual o conteúdo deve ser aplicado, sendo considerado o nível de dificuldade e tempo necessário para a montagem. Foram selecionadas as professoras das escolas, e no primeiro encontro com elas, foi desenvolvido cinco aulas, explicando como funcionaria todo o processo e metodologia do projeto. Com uma análise mais profunda sobre o particular de cada uma. Obteve-se que as profissionais possuem idade entre 22 e 43 anos, com experiência de 2 a 12 anos nas escolas. Em relação ao projeto, relataram que tiveram curiosidade e interesse sobre como seriam desenvolvidas as atividades, pois o material utilizado é diferenciado e cada montagem possui um novo desafio. Após o encontro com as professoras, foram distribuídos os encontros com as alunas em dias da semana que elas podiam ir até a Universidade, foi apresentado o projeto para elas e a montagem de kits com aplicação de conteúdo. As alunas do projeto possuem idades de 14 a 17 anos, do $9^{\circ}$ ano ao $2^{\circ}$ ano do ensino médio. Residem em diversos bairros do município, localizadas em regiões centrais, periféricas e zona rural. A profissão dos pais, são variadas predominando de mecânico e safristas. Verificou-se que não haviam participado de projetos anteriormente, e relataram que aceitaram participar porque gostam da área das ciências, para adquirir novos conhecimentos, aprender de forma prática e ajudar na escolha da profissão. Todas desejam cursar o ensino superior, algumas já escolheram o curso, outras possuem mais de uma opção e algumas não sabem ainda o que cursar. Citaram profissões como: Engenharia civil, medicina, dança, matemática, direito, estilista, fotografia e letras. O processo de seleção foi feito pelas professoras das escolas e observados requisitos como participação em aula, boas notas, bom comportamento e boa aprendizagem. Com mais de um encontro com as alunas, as aulas foram desenvolvidas e foi enfatizado sobre a responsabilidade que elas tinham em aprender para depois compartilhar o conhecimento com os outros alunos das escolas. Foi possível observar que assim como numa sala de aula, as alunas não possuem um ritmo equivalente, ou seja, umas montavam mais rápido que as outras e isso é válido também para o entendimento dos conteúdos aplicados. Mas todas, no seu tempo, realizaram as atividades propostas, participaram e mostraram interesse em participar do projeto. O projeto passa a todas as bolsistas o sentimento de valorização, para as professoras estaduais que vivem num momento delicado profissionalmente e principalmente as alunas que na sua maioria são de famílias humildes e nunca participaram de um projeto como esse. Destaca-se quão grandioso é o projeto por ter a presença de três alunas bolsistas surdas acompanhadas da professora intérprete, o fato de fazer com que elas se sintam útil em um mundo em que o diferente é muitas vezes excluído, é encantador. Como tudo que é novo o projeto passou insegurança, mas no decorrer de seu andamento tudo foi fluindo e acontecendo de forma excepcional. Com um momento de recesso foi possível associar todos os acontecimentos, refletir sobre o projeto e observar que o contato com a ciência e tecnologia deve ser precoce e ser desenvolvido de maneira significativa, ainda na escola. Assim, as alunas irão mudar a concepção sobre gostar e desejar cursar ou não o ensino superior na área das ciências exatas. (LA SALLES, K.; LA SALLES, W.; FERREIRA; SOUSA; RIBEIRO 2019). Retornou-se com o desenvolvimento das aulas com as alunas, afinal elas precisavam estarem preparadas para passar a diante o que lhes foi ensinado, com muita dedicação e compromisso. A maioria das alunas foram em todos os encontros e desenvolveram com êxito as propostas. Enfim, depois da preparação chegou o grande momento de implantar o 
projeto nas escolas e conhecer a realidade de cada uma delas. Apesar de todas as escolas serem estaduais, elas são diferentes tanto no aspecto físico como no ensino. Porém, o projeto foi bem acolhido por todas, em algumas foram organizadas salas exclusivas para o projeto e outras onde foi possível. A entrega dos kits foi um momento gratificante, pois era hora de ver o retorno do que tinha sido desenvolvimento anteriormente. Lá estavam elas, todas as meninas, todas com a camiseta rosa das meninas nas ciências, fazendo parte de um projeto de desenvolvimento de habilidades da engenharia, mas também social. Depois da organização dos dias da semana que o projeto seria desenvolvido nas escolas, foi dado um tempo para as alunas se adaptarem, e com liberdade de realizar seus primeiros encontros, como mostra a figura 2. Foram feitas visitas para ver o andamento do projeto e conhecer os outros alunos que fazem parte, sendo um deles autista. As alunas agora estão preparadas para apresentarem ideias consistentes sobre solucionar problemáticas. Assim, o projeto tomou forma, e vai se desenvolvendo buscando trazer cada vez mais meninas nas ciências.

Figura 2: Alunas ensinando colegas na Escola.

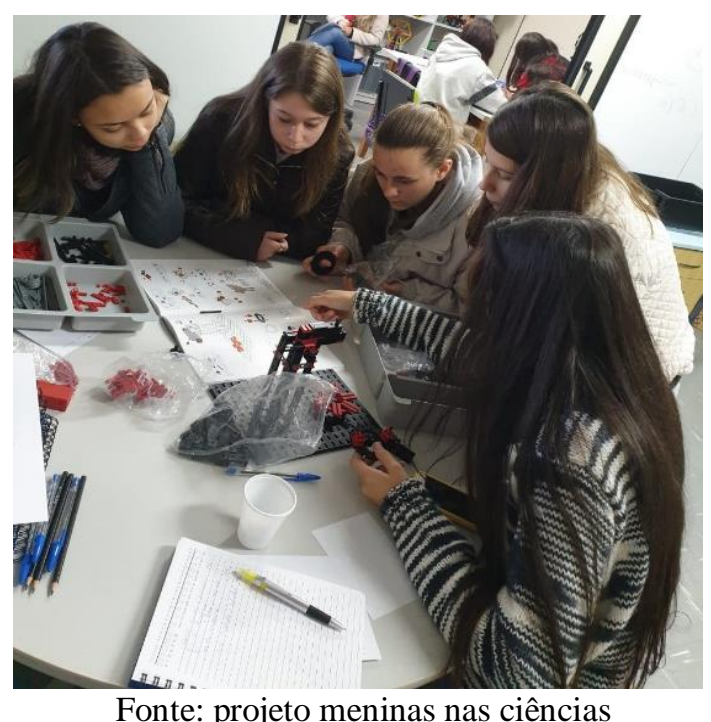

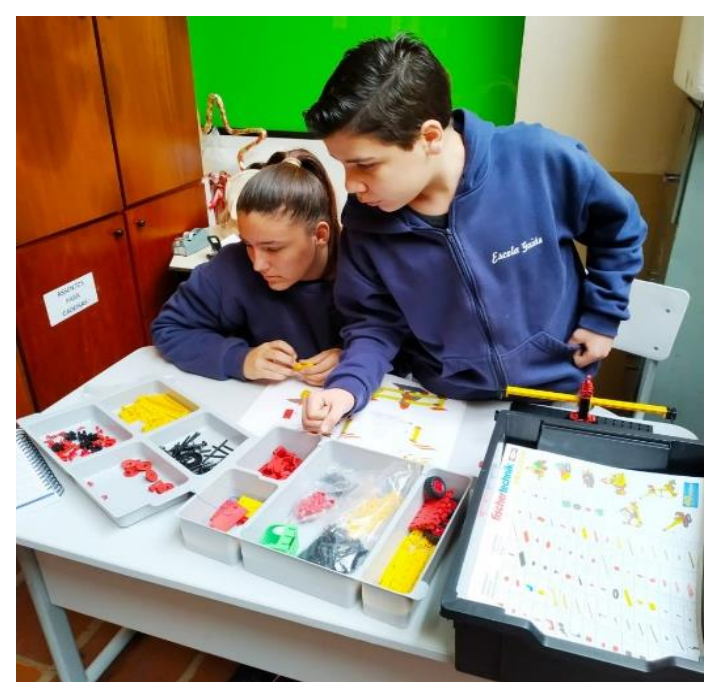

Fonte: projeto meninas nas ciências

Além disso, o projeto oferece para as professoras e alunas oficinas e visitas aos laboratórios das engenharias, demonstrado nas figuras 4, 5 e 6 . Sendo elas, no laboratório da Engenharia Mecânica sobre motores e componentes e no Laboratório de Solos e Estruturas sobre estruturas e construção, os responsáveis de cada laboratório explicaram o funcionamento. Ressalta se que para a maioria das alunas foi o primeiro contato com a Universidade, sendo visível um certo deslumbramento. Também foi desenvolvida oficina sobre Mecânica básica de forma simples e prática sobre alguns conceitos. Com um público de 35 pessoas das escolas participantes do projeto e com transporte gratuito foi ofertada a oficina sobre materiais de construção civil, a sustentabilidade e visitas aos laboratórios. Contudo, foi demonstrado pelas as alunas o interesse em futuramente ingressar no ensino superior na área das ciências. 
Figura 4: Oficina sobre materiais de construção civil e a sustentabilidade.

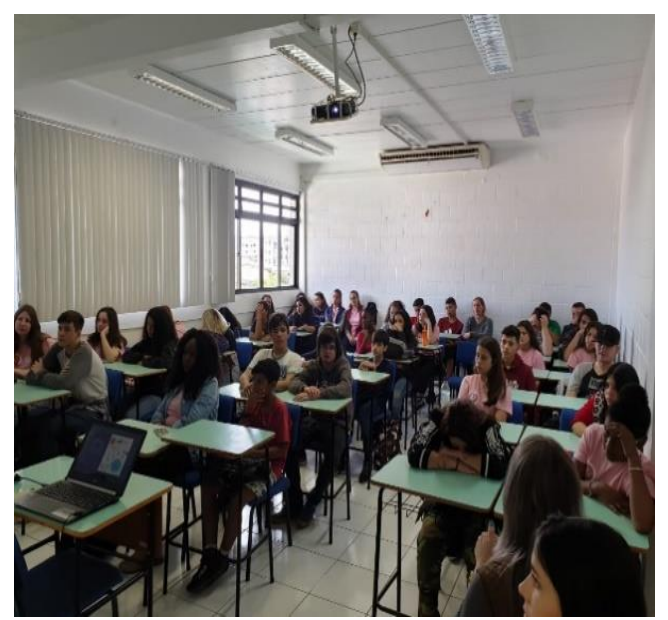

Fonte: projeto meninas nas ciências

Figura 5: Oficina de materiais.

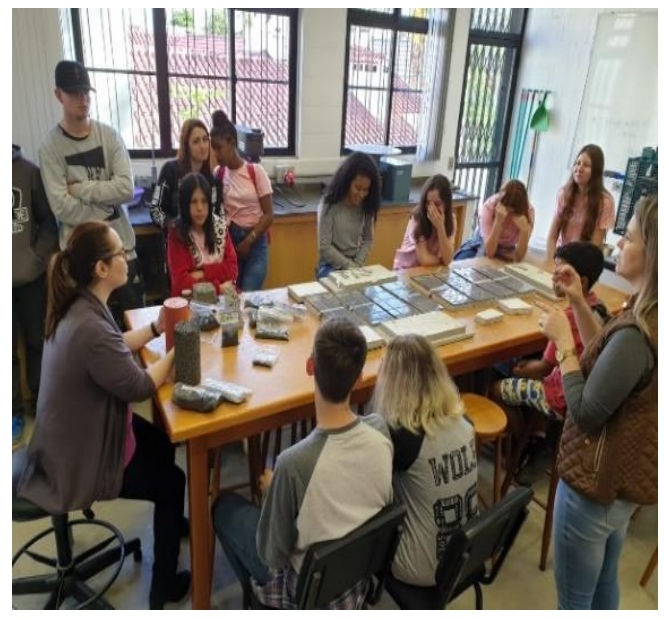

Fonte: projeto meninas nas ciências

Figura 6: Laboratório de tecnologia de tratamento de efluentes e resíduos sólidos.

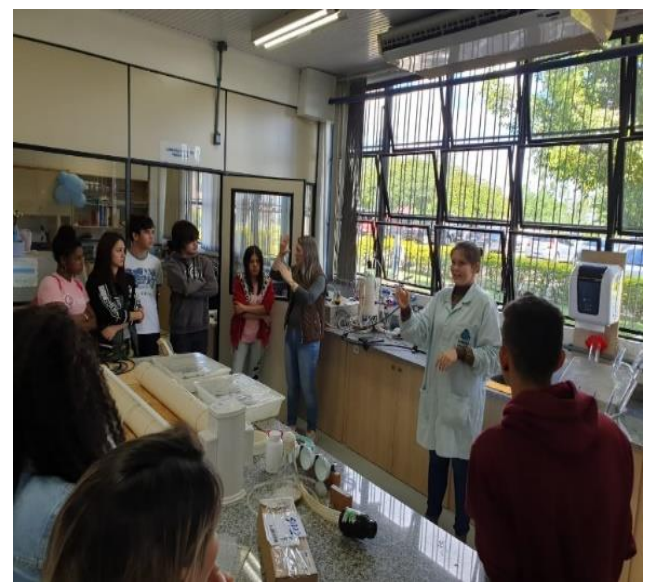

Fonte: projeto meninas nas ciências 


\section{CONSIDERAÇÕES FINAIS}

O projeto faz parte de uma evolução de muitos anos que caminha em passos lentos, porém firmes, carrega o orgulho de tantas mulheres que lutaram para que hoje a presença feminina fizesse parte de profissões consideradas masculinas. Os estudos comprovam que a evolução é árdua e deve ser contínua, pois está havendo melhoria. Vencer tradições passadas e quebrar paradigmas é um diferencial do projeto. O recebimento dos kits, a escolha das bolsistas, desenvolvimento das aulas, visita as escolas, todo um trabalho de adaptação e compromisso para fazer a diferença. Proporcionar essa experiência para alunas de escolas públicas é algo grandioso, pois sabe-se que nem todas as pessoas possuem oportunidades. O projeto também possibilita a inclusão social de meninas com deficiência auditiva, o que torna o projeto meninas nas ciências ainda mais especial e diferenciado. Sendo que ainda não tenham muitas instituições que consigam adequar seu ensino para este atendimento, o projeto proporcionou a essas meninas a oportunidade de estarem na Universidade e fazer com que elas se sintam importantes repassando seus aprendizados para os colegas, motivando-as a perderem o receio de futuramente se inserirem no ensino superior. Podemos definir como gratificante, pois além de todos os objetivos visíveis como, trazer meninas para as engenharias, proporcionar o primeiro contato com a Universidade, com oficinas e laboratórios, o que mais pode ser destacado é a valorização das participantes. Além de cumprir seu protocolo profissional busca tocar de forma significativa a vida dessas meninas. Aproximadamente 150 alunos foram envolvidos no Projeto Meninas nas Ciências, a ideia deve seguir e ser exemplo para que surjam novos projetos como esse, para que faça diferença na vida de meninas que sonham e acreditam em seus ideais, e que principalmente desenvolvam habilidades nas engenharias.

\section{REFERÊNCIAS BIBLIOGRÁFICAS}

As mulheres no mundo da ciência e do trabalho: reflexões sobre um saber-fazer / Isabel C. Lousada, Márcio Matiassi Cantarin (organizadores). 1.ed. - Curitiba : Appris, 2020. 249 p.; $23 \mathrm{~cm}-$ ( Ciências sociais)

BARROWS, H. S. A Taxonomy of Problem-Based Learning methods. Medical Education, v.20, p. 481-486, 1986.

BRUSCHINI, C.; LOMBARDI, M. R. A bipolaridade do trabalho feminino no Brasil contemporâneo. Cadernos de Pesquisa, n. 110, p. 67-104, jul. 2000. Disponível em: Acesso em: 01 mar. 2020.

FREIRE, P. Pedagogia do Oprimido. Rio de Janeiro: Paz e Terra, 1987.

LA SALLES, K. S. T. da S. de; LA SALLES, W. F. de; FERREIRA, M. S.; SOUSA, J. K. C.; RIBEIRO, P. R. de A.. Despertando vocações para as carreiras de exatas e tecnologia: o projeto sarminina cientistas. Universidade Federal do Maranhão. COBENGE 2019.

MANENTE, M. V.; RODRIGUES, O. M. P. R.; PALAMIN, M. E. G. Deficientes auditivos e escolaridade: fatores diferenciais que possibilitam o acesso ao ensino superior. Rev. bras. 
educ. espec. [online]. 2007, vol.13, n.1, pp.27-42. ISSN $1413-6538$. https://doi.org/10.1590/S1413-65382007000100003.

MORAES, A. Z. de; CRUZ, T. M. Estudantes de engenharia: entre o empoderamento e o binarismo de gênero. Cad. Pesqui., Jun 2018, vol.48, no.168, p.572-598. ISSN 0100-1574 Disponível em: Acesso em: 01 mar. 2020.

SCHWANTES, C. C. M.; ANDRADE, V. C. Mulheres no campo da pesquisa em Física e Ciências Exatas na contemporaneidade. In: Mulheres e violências: interseccionalidades. Org.: STEVENS, C.; OLIVEIRA, S.; ZANELLO, V.; SILVA, E.; PORTELA, C. Brasília, DF: Technopolitik, 2017. 628 p. Site: http://lattes.cnpq.br/web/dgp/pesquisadores-por-sexo Acesso em: 02. Mar. 2020.

\title{
GIRLS IN SCIENCES: DEVELOPING SKILLS FOR INSERTION IN ENGINEERING SINCE SCHOOL
}

\begin{abstract}
Engineering is a driving force behind development and has the potential to provide society with solutions to problems. However, it appears that in this area, considered essentially male, the distribution profile is very uneven. Thus, expanding female participations in scientific activities in the technological areas, especially in engineering, is a need that requires specific actions. In this way, the project Girls in Sciences: Developing Engineering Skills at the University of Santa Cruz do Sul and funded by CNPq, aims to develop engineering skills and knowledge, stimulate and promote the encouragement of women in the area. Teachers and students from five public schools in the municipality of Santa Cruz do Sul were selected, and they develop specific projects that take place in workshops held within the university's engineering laboratories and in schools. Seeking knowledge and the discovery of the basic principles of engineering, using the use of assembly kits, which allows the simulation of construction of experiments, there is an interaction with objects that are in high school and higher education disciplines. Thus, the project offers an environment of technical-scientific knowledge, development of critical sense and experimentation of the studied concepts, focusing on the technological area and encouraging the entry of students in the field of science and engineering. Serving as a driver for the inclusion of women in the world of science and work.
\end{abstract}

Keywords: Engineering, girls, education, entrepreneurship, social inclusion. 